\title{
Synthesis, characterization, and in vitro release of oxytetracycline loaded in pH-responsive $\mathrm{CaCO}_{3}$ nanoparticles
}

\author{
Sherifat Banke Idris ${ }^{1,6}$, Arifah Abdul Kadir ${ }^{*}$, Faez Firdaus Abdullah Jesse ${ }^{2}$, Siti Zubaidah Ramanoon ${ }^{3}$, Muhammad Abdul Basit ${ }^{1,7}$, \\ Zainul Amiruddin Zakaria ${ }^{4}$, Md Zuki Abu Bakar Zakaria ${ }^{1,5}$ \\ ${ }^{1}$ Department of Veterinary Preclinical Sciences, Faculty of Veterinary Medicine, Universiti Putra Malaysia, Serdang, Malaysia. \\ 2Department of Veterinary Clinical Studies, Faculty of Veterinary Medicine, Universiti Putra Malaysia, 43400 UPM Serdang, Malaysia. \\ ${ }^{3}$ Department of Farm and Exotic Animal Medicine and Surgery, Faculty of Veterinary Medicine, Universiti Putra Malaysia, 43400 UPM Serdang, Malaysia. \\ ${ }^{4}$ Department of Biomedical Sciences, Faculty of Medicine and Health Sciences, Universiti Putra Malaysia, 43400 UPM Serdang, Malaysia. \\ ${ }^{5}$ Institute of Biosciences, Universiti Putra Malaysia, 43400 UPM Serdang, Malaysia. \\ ${ }^{6}$ Department of Veterinary Pharmacology and Toxicology, Faculty of veterinary Medicine, Usmanu Danfodiyo University, Sokoto, Nigeria. \\ ${ }^{7}$ Department of Biosciences, Faculty of Veterinary Sciences, Bahauddin Zakariya University, Multan, Pakistan.
}

\section{ARTICLE INFO \\ Received on: 18/03/2019 \\ Accepted on: 06/06/2019 \\ Available online: 04/11/2019}

\section{Key words:}

$\mathrm{CaCO}_{3}$ nanoparticle, oxytetracycline, morphological characterization, drug loading, in vitro release.

\begin{abstract}
Alternative drug delivery for the treatment of resistant bacterial infections is necessary to bypass existing antibiotic resistance mechanism and ensure direct delivery of the drug to the targeted site using locally sourced materials to minimize cost in the long term. In this study, cockle shell-derived calcium carbonate aragonite nanoparticles $\left(\mathrm{CS}-\mathrm{CaCO}_{3} \mathrm{NP}\right)$ was synthesized, loaded with oxytetracycline (OTC), and characterized using Zeta analysis, Transmission electron microscopy (TEM), FESEM, X-ray Diffraction (XRD), Fourier Transform Infrared (FTIR) and Brunauer-Emmett-Teller analysis. The loaded OTC-CS-CaCO $\mathrm{NP}_{3}$ was further characterized after which the in vitro release of OTC was studied. A homogenously spherical CS-CaCO ${ }_{3} \mathrm{NP}$ was observed on TEM with a mean diameter of $29.90 \mathrm{~nm}$ and -19.9 zeta potential which increased to $62.40 \mathrm{~nm}$ and -23.5 , respectively, after OTC loading. XRD and FTIR analysis of OTC-CS- $\mathrm{CaCO}_{3} \mathrm{NP}$ revealed that OTC maintained its functionality and crystallinity. The formulation of OTC:CS-CaCO${ }_{3} \mathrm{NP}$ in ratio 1:4 with drug encapsulating efficiency $(71 \%)$ was used for in vitro release studies. OTC was sustainably released from OTC-CS-CaCO 3 NP over a period of 96 hours. Our results suggest that OTC-CS$\mathrm{CaCO}_{3} \mathrm{NP}$ is a promising nanoparticle antibiotic delivery system with efficient physicochemical and pharmacological properties whose antibiotic properties should be further investigated.
\end{abstract}

\section{INTRODUCTION}

Cockle shells derived from bivalve mollusks or Anadara granosa are a waste product of Malaysian aquaculture industry (Othman et al., 2013). The quest to reduce waste and looking inwards for alternative uses of this abundant natural reserve of calcium carbonate, the main chemical constituent of cockle shells, has resulted in its wide application in the field of engineering, pharmacology, and medicine (Razalia et al., 2016).

"Corresponding Author

Arifah Abdul Kadir, Department of Veterinary Preclinical Sciences Faculty of Veterinary Medicine, Universiti Putra Malaysia, Serdang, Malaysia. E-mail:arifah@upm.edu.my
Biocompatibility of calcium carbonate has been described and this makes it a perfect candidate for nano drug delivery (Kamba et al., 2013). Direct bactericidal activity of nanoparticles which results in improved therapeutic index and efficacy has prompted the loading of antibiotics into calcium carbonate nanoparticles with the aim of better treatment while reducing costs (Isa et al., 2016; Saidykhan et al., 2016).

Oxytetracycline (OTC) is a very common antibiotic widely used in veterinary medicine for the treatment of bacterial infections caused by both Gram-positive and Gram-negative organisms; however, the emergence of resistant strains has questioned its therapeutic effects (Larbi-Bouamrane et al., 2016). Employing the use of nanoparticles to deliver antibiotics in the treatment of bacterial infections has yielded good results due to the 
unique properties of nanoparticles such as ultra-small size, large surface to mass area, and bacterial membrane adhering properties (Adhikari et al., 2013). More so, the successful synthesis of nanoparticles loaded drug with right physicochemical properties for effective in vitro and in vivo interactions rely on the methods of synthesis. Different methods of synthesizing nanoparticles have been described and all revolve mainly around a top- or bottomdown approach. For the top-down approach, the fabrication of nanoparticles usually starts from the large-sized raw material and is broken down to the level of desired size of nanoparticles as the end product or from a bottom-up approach where individual elements to make diverse fine nanoparticles are synthesized from scratch, while the bottom down approach entails the synthesis of these nanoparticles from individual elements (Dhand et al., 2015; Priyadarshana et al., 2015). Three processes are basically used for the synthesis, namely, physical, biological, and mechanical process. In the physical method, heat, gas, and vapor are applied to the precursors of the different nanoparticles through processes like gas condensation, vacuum deposition and vaporization, laser pyrolysis, melt mixing, and high energy ball rolling mill (Rawat et al., 2016). The biological process involves the synthesis of nanoparticles from some microorganisms or plants while the chemical process involves nanoparticles fabrication via polyol synthesis, microemulsion technique, sol gel, and chemical vapor (Dhand et al., 2015).

Using the right method of synthesis, we, therefore, hypothesize that oxytetracycline will retain its physicochemical and pharmacological properties when loaded into cockle shell-derived calcium carbonate aragonite nanoparticles (CS$\left.\mathrm{CaCO}_{3} \mathrm{NP}\right)$. In this study, we synthesized (CS-CaCO$\left.{ }_{3} \mathrm{NP}\right)$ by a topdown approach, loaded it with oxytetracycline, and characterized it for use against livestock resistant bacteria species.

\section{MATERIALS AND METHODS}

\section{Synthesis of CaCO3 nanoparticles from cockle shell powder}

Cockle shell was washed and milled mechanically to get micron-sized cockle shell powder as described by Danmaigoro et al. (2017). The prepared micron size cockle shell powder was further processed; thus, $2 \mathrm{~g}$ of $75 \mu \mathrm{m}$ micron-sized powder of CS$\mathrm{CaCO}_{3}$ powder was weighed with an electronic balance (Biobase, BA 2204 B) and put in a flat bottom flask with a magnetic stirring bar within it. $50 \mathrm{ml}$ of deionized water was added to the powder. The resultant solution was stirred on a systematic multi hot plate stirring machine (Systematic Multi-Hotplate Stirrers 6 Positions, WiseStir ${ }^{\circledR}$ Korean $)$ set at $1,000 \mathrm{rpm}\left(27^{\circ} \mathrm{C}\right.$ for 2 hours $)$. After 5 minutes of agitation, $0.5 \mathrm{ml}$ of dodecyl dimethyl betaine (BS-12) Sigma-Aldrich (Steinheim, Germany) was added gradually into the solution and covered with aluminum foil. After 2 hours of stirring, the solution was filtered with filter paper of diameter $18.0 \mathrm{~cm}$ and the surfactant rinsed off through the filter paper with double deionized water, leaving the sediments which are the nanoparticles on the filter paper. This was then allowed to dry for 3 days in the oven at $50^{\circ} \mathrm{C}$. The dried newly synthesized nanoparticle was placed in a cylindrical jar of $8 \mathrm{~cm}$ in diameter (with a $7 \mathrm{~cm}$ flat iron fixed perpendicular to it) containing 15 ceramic balls and placed on a roller mill at $200 \mathrm{rpm}$ for three consecutive days overnight (54 hours). The resulting fine $\mathrm{CS}-\mathrm{CaCO}_{3}$ nanoparticle was then packed in glass bottles and stored in the oven at $50^{\circ} \mathrm{C}$ till further analysis.

\section{Loading of oxytetracycline into synthesized $\mathrm{CS}-\mathrm{CaCO}$ nanoparticles}

The loading of oxytetracycline was done by mixing the free oxytetracycline and the right concentration of synthesized $\mathrm{CS}-\mathrm{CaCO}_{3} \mathrm{NP}$ with the aid of lab multistirrer (Systematic MultiHotplate Stirrers 6 Positions, WiseStir ${ }^{\circledR}$ Korean) overnight at room temperature set at $200 \pm 1 \mathrm{rpm}$. After overnight mechanical agitation, the suspensions of the OTC-CS-CaCO${ }_{3} \mathrm{NP}$ formulation was centrifuged at 20,000 rpm for 15 minutes. Supernatant from formulation was kept in a separate tube, while the pellet (OTC-CS$\mathrm{CaCO}_{3} \mathrm{NP}$ ) was washed, dried, and analyzed for morphological characteristics.

\section{Morphological characterization of synthesized CS-CaCO3NP and OTC-CS-CaCO3N}

The average Zeta size, charge, and polydispersity index (PDI) of the synthesized CS-CaCO $\mathrm{NP}_{3}$ and OTC-CS-CaCO $\mathrm{NP}$ was done by dynamic light scattering technique using a Zetasizer Nano ZS, Malvern Instruments (Malvern Version 7.02, Malvern Instruments Ltd. UK). Briefly, $0.1 \mathrm{mg}$ of freshly prepared CS$\mathrm{CaCO}_{3} \mathrm{NP}$ and OTC-CS-CaCO $\mathrm{NP}_{3}$ was dissolved in a test tube containing $10 \mathrm{ml}$ of de-ionized water and was sonicated (Power Sonic $505^{\circledR}$ ) for 20 minutes. $2 \mathrm{ml}$ of the supernatant was gently aspirated into a syringe, fitted with a TRP ${ }^{\circ}$ Spritzen-/syringe filter $0.45 \mu \mathrm{m}$ and then fixed to the cuvette which was subsequently loaded into the machine. Measurements were taken in triplicates at a light scattering angle of $90^{\circ} \mathrm{C}$ at $25^{\circ} \mathrm{C}$.

The shape and particle size distribution of the synthesized $\mathrm{CS}-\mathrm{CaCO}_{3} \mathrm{NP}$ and OTC-CS-CaCO${ }_{3} \mathrm{NP}$ was determined using transmission electron microscopy (TEM) (IUPAC) while the surface morphology was done by field emission scanning electron microscopy (FESEM) equipped with an energy-dispersive X-ray spectroscopy unit. The specific surface area of $\mathrm{CS}-\mathrm{CaCO}_{3} \mathrm{NP}$ was determined by the Brunauer-Emmett-Teller (BET) technique via a 3-flex surface characterization analyzer (Micromeritrics, Instrument Corporation, USA) using a total $\mathrm{CS}-\mathrm{CaCO}_{3} \mathrm{NP}$ weight of 0.2 g. X-ray powder diffractometer (Shimadzu XRD-6000 powder diffractometer) using $\mathrm{CuK} \alpha(\lambda=1.540562 \AA)$ at $40 \mathrm{kV}$ and $30 \mathrm{~mA}$ was used to investigate the crystallinity of $\mathrm{CS}-\mathrm{CaCO}_{3} \mathrm{NP}$, OTC-CS-CaCO $\mathrm{NP}_{3}$, and OTC alone. The crystallinity phase of the samples was done at different diffraction angles ranging from $2^{\circ}$ to $60^{\circ}$, set at $0.02^{\circ} /$ seconds in $2 \Theta$ at $37^{\circ} \mathrm{C}$ (Saidykhan et al., 2016). Functional group endings of the $\mathrm{CS}-\mathrm{CaCO}_{3} \mathrm{NP}$, OTC$\mathrm{CS}-\mathrm{CaCO}_{3} \mathrm{NP}$, and OTC alone was determined using Fouriertransform infrared spectroscopy (Model 100 series, Perkin Elmer) at a range of 4,000 to $280 \mathrm{~cm}^{-1}$ with a resolution of $2 \mathrm{~cm}^{-1}$ and an average scan of 64 times.

\section{Determination of OTC loading content and encapsulation efficiency}

Six formulations of OTC-CS-CaCO $\mathrm{NP}_{3}$ loading were prepared. The first set comprised of three increasing doses of free OTC against the same three doses of $\mathrm{CS}-\mathrm{CaCO}_{3} \mathrm{NP}$ to make a $1: 1,2: 1$, and $3: 1$ ratio of OTC:CS-CaCO${ }_{3} \mathrm{NP}$. The second set consists of three increasing doses of $\mathrm{CS}-\mathrm{CaCO}_{3} \mathrm{NP}$ with the same 
three doses of free OTC in 1:2, 1:3, and 1:4 OTC:CS-CaCO${ }_{3} \mathrm{NP}$ ratio, respectively. The absorbance of the supernatants at $353 \mathrm{~nm}$ using ultraviolet-visible (UV-Vis) spectrophotometer (Shimadzu UV 1800) was measured and the concentration of the unloaded free OTC in all the supernatants was then determined using the equation generated from standard calibration curve for OTC at 353 nm (Fig. 1).

After which the loading content (LC) and encapsulation efficiency (EE) was calculated using Equations (1) and (2), respectively. The analyses of LC and EE was expressed as the mean percentage \pm standard deviation (SD) based on two formulations that yielded similar results:

$$
\begin{aligned}
& \operatorname{LC}(\%)=W_{\mathrm{t}}-W_{\mathrm{f}} / W_{\mathrm{np}} \times 100 \\
& \operatorname{EE}(\%)=W \mathrm{t}-W_{\mathrm{f}} / W_{\mathrm{t}} \times 100
\end{aligned}
$$

where $W_{\mathrm{t}}$ is the total weight of drug fed, $W_{\mathrm{f}}$ is the weight of non-encapsulated free drug, and $W_{\mathrm{np}}$ is the weight of nanoparticles. The results of drug loading were generated from the average of two independent experiments (Saidykhan et al., 2016).

\section{In vitro drug release study of the OTC form OTC-CS-CaCO3NP}

The profile of free OTC released from OTC-CS$\mathrm{CaCO}_{3} \mathrm{NP}$ was determined using the method of Chakraborty et al. (2012) with modifications. A total of $10 \mathrm{mg}$ of free OTC and OTC-CS-CaCO ${ }_{3} \mathrm{NP}$ was placed in a dialysis tube of $22 \mathrm{~mm}$ $\times 32$ feet dry diameter (Thermo Scientific USA) and suspended in a glass jar containing $200 \mathrm{~mL}$ deionized water of four different $\mathrm{pH}$ ( $\mathrm{pH} \mathrm{4,} \mathrm{6,} \mathrm{7.4,} \mathrm{and} \mathrm{8).} \mathrm{The} \mathrm{glass} \mathrm{jar} \mathrm{was} \mathrm{covered} \mathrm{and} \mathrm{placed}$ on a lab multistirrer (WiseCube ${ }^{\circledR}$ WIS-10; Wisd Laboratory Instruments, Witeg, Germany) at $37^{\circ} \mathrm{C} \pm 0.5^{\circ} \mathrm{C}$ at $120 \pm 1 \mathrm{rpm}$ for 4 days ( 96 hours). At calculated time spans of 1 to 8 hours and then 24, 48, 72, and 96 hours, respectively, 1,000 $\mu 1$ of the solution was withdrawn and replaced by an equal amount of fresh deionized water of the equivalent $\mathrm{pH}$ to maintain a sink condition. The concentration of OTC released was determined at $353 \mathrm{~nm}$ (wavelength) using an UV-Vis spectrophotometer. The absorbance was interpreted according to an OTC standard calibration curve. The release study was conducted until there was an apparent total release of OTC. The percentage of OTC released was calculated based on the amount of OTC released at a given time to the amount of OTC loaded in OTC-CS$\mathrm{CaCO}_{3} \mathrm{NP}$ expressed mathematically below. The results obtained was plotted on a graph of cumulative percentage of drug release versus time intervals.

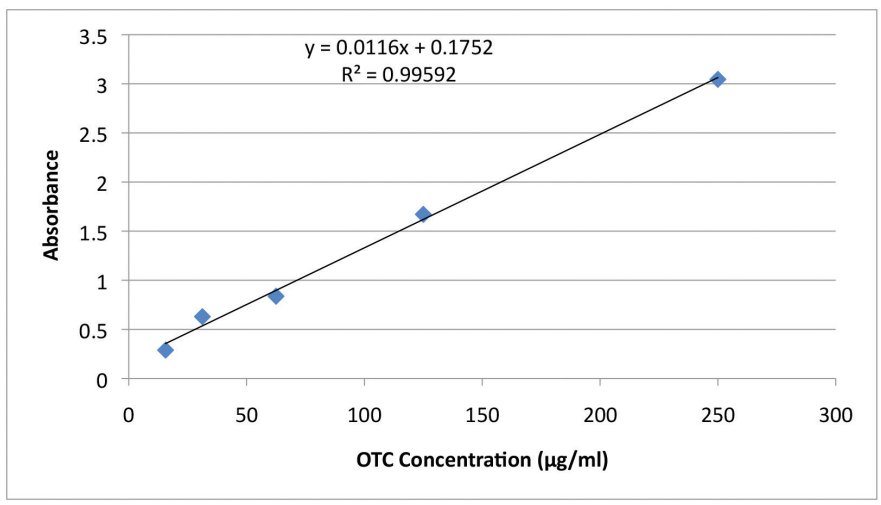

Figure 1. OTC standard curve at $353 \mathrm{~nm}$.
Amount of OTC released $(\mathrm{mg})=$

(Concentration derived from standard curve mcg $\times$ volume of dissolution medium)

1000

Percentage OTC released $=$

$\frac{\text { Amount of OTC released }(\mathrm{mg})}{\text { Total amount of OTC inOTC-CS-CaCO3NP) }} \times 100$

OTC-CS-CaCO3NP) $\times 100$

Cumulative percentage OTC released $=\mathrm{P}(\mathrm{t}-1)+\mathrm{Pt}$

where $P_{t}=$ Percentage OTC released at time $t$; $\mathrm{P}\left({ }_{t-1}\right)=$ percentage OTC released at time 1 .

\section{Statistical analysis}

All data obtained were expressed as mean \pm SD except for the elemental percentages which were expressed as mean \pm standard mean of error (SEM).

\section{RESULTS AND DISCUSSION}

\section{Zeta size, zeta potential, and polydispersity index (PDI)}

The characterization of nanoparticles based on physicochemical properties such as size, shape, charge, and dispersity are important steps to understand it pharmacokinetics and biodistribution in biological medium (Murdock et al., 2008). These physicochemical properties are the basic determinants of effective drug loading, controlled release, pharmacokinetics, efficacy, and toxicity, as well as bacterial cell internalization. Table 1 and Figures 2-5 show the zeta size, zeta potential, and PDI of CS-CaCO ${ }_{3} \mathrm{NP}$ and OTC-CS-CaCO${ }_{3} \mathrm{NP}$. The zeta size of $\mathrm{CS}-\mathrm{CaCO}_{3} \mathrm{NP}$ range from 93 to $98 \mathrm{~nm}$ while higher size (268$280 \mathrm{~nm}$ ) was observed for OTC-CS-CaCO $\mathrm{NP}_{3}$. The average zeta size $(95.96 \mathrm{~nm})$ of the synthesized $\mathrm{CS}-\mathrm{CaCO}_{3} \mathrm{NP}$ is within the limit $(<100 \mathrm{~nm})$ for which $\mathrm{CaCO}_{3} \mathrm{NP}$ sizes $<100$ can be classified as nanometer-level particle, and this size usually enables the dispersion of drugs loaded within them (Pan et al., 2018). Higher zeta size of $142 \mathrm{~nm}$ for $\mathrm{CaCO}_{3} \mathrm{NP}$ has been reported

Table 1. Effect of dynamic light scattering on $\mathrm{CS}-\mathrm{CaCO}_{3} \mathrm{NP}$ and OTC-CS-CaCO${ }_{3} \mathrm{NP}$.

\begin{tabular}{lccc}
\hline Nanoparticle & Average Zeta size(nm) & Zeta potential & PDI \\
\hline CS-CaCO3NP & $95.96 \pm 2.7$ & $-19.9 \pm 1.27$ & 0.36 \\
OTC-CS-CaCO3NP & $276.00 \pm 6.3$ & $-23.5 \pm 1.10$ & 0.33 \\
\hline
\end{tabular}

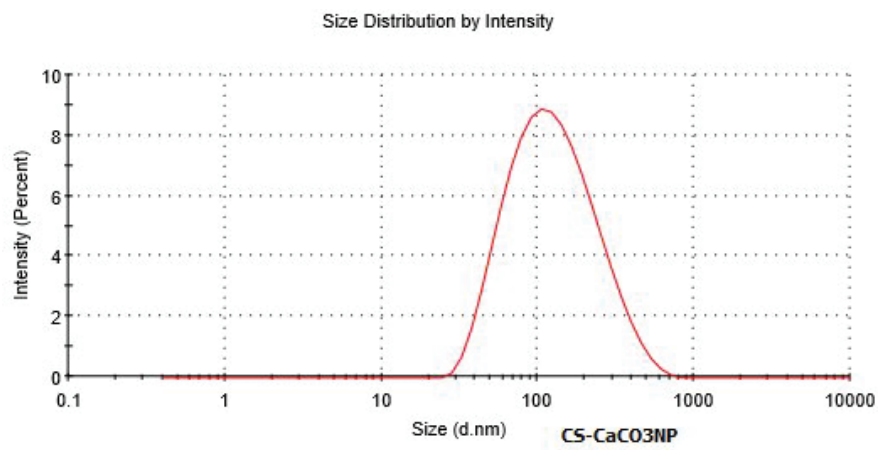

Figure 2. Zeta size distribution of $\mathrm{CS}-\mathrm{CaCO}_{3} \mathrm{NP}$. 
(Danmaigoro et al. 2017). The inclusion of BS-12 and longer period of milling ball impact on the power contributed to the lower zeta size and PDI observed. Higher size has always been associated with the agglomeration of the nanoparticles; however, the use of BS-12, a zwitterionic surfactant which acts as a capping agent, improved the dispersion of the $\mathrm{CaCO}_{3} \mathrm{NP}$, hence resulting in lower zeta size. The presence of a metal at a $90^{\circ}$ angle in the ceramic jar increases the kinetic energy of the ceramic balls on one another as they strike the metal and further break the bonds in the $\mathrm{CS}-\mathrm{CaCO}_{3} \mathrm{NP}$ in the controlled energy ball milling mechanical process also contributed to further grind the $\mathrm{CS}-\mathrm{CaCO}_{3} \mathrm{NP}$ in the controlled energy ball milling mechanical process also contributed to further spreading and reducing the size of the nanoparticles generated from the cockle shell powder (Dhand et al., 2015). Low PDI values have been reported for $\mathrm{CS}-\mathrm{CaCO}_{3} \mathrm{NP}$ from different studies (Isa et al., 2016; Saidykhan et al., 2016) and it is an indicator of the spread of size distribution of the nanoparticles (Faustino-Vega et al., 2009; Masarudin et al., 2015).

The zeta potential of $\mathrm{CS}-\mathrm{CaCO}_{3} \mathrm{NP}$ and OTC-CS$\mathrm{CaCO}_{3} \mathrm{NP}$ fall within the range $(-25 \mathrm{mV}$ and $+25 \mathrm{mV})$ of aggregation for nanoparticles due to the weak Van Der Waal nanoparticle forces existing between the nanoparticles. The loading of oxytetracycline further increased the zeta charge almost close to the higher limit (Fig. 5) which requires greater force in bringing two particles together. A higher negative potential of OTC-CS$\mathrm{CaCO}_{3} \mathrm{NP}$ is suggestive of adsorption of negatively charged OTC on the internal surfaces of the $\mathrm{CS}-\mathrm{CaCO}_{3} \mathrm{NP}$ making the OTC-CS$\mathrm{CaCO}_{3} \mathrm{NP}$ more nano stable and remain longer in circulation with a reduced degree of agglomeration (Das et al., 2011; FaustinoVega et al., 2009). The negative surface charge of CS-CaCO ${ }_{3} \mathrm{NP}$ is also responsible for its interaction in vivo as negative nanoparticles have a prolonged systemic time compared to positive ones with very high clearance time (Arvizo et al., 2011).

\section{CS-CaCO3NP and OTC-CS-CaCO3NP morphology}

The overall morphology of the synthesized nanoparticles was assessed using TEM and FESEM. The former providing information on particles size while the latter give shape and appearance (Liu et al., 2010). The TEM revealed the average size of $29.90 \pm 6.3 \mathrm{~nm}$ within the range of $17.6-41 \mathrm{~nm}$ for CS$\mathrm{CaCO}_{3} \mathrm{NP}$ (Figs. 6 and 7) while OTC-CS-CaCO${ }_{3} \mathrm{NP}$ showed a mean size of $62.4 \pm 20.68 \mathrm{~nm}$ within the range of $23.02-81.50$ nm (Figs. 8 and 9). Results of the FESEM analysis revealed a consistent spherical shape with a porous surface and solid or dense appearance for $\mathrm{CS}-\mathrm{CaCO}_{3} \mathrm{NP}$ and OTC-CS-CaCO${ }_{3} \mathrm{NP}$, respectively (Figs. 10 and 11). The shape, size, and overall morphology of the CS-CaCO${ }_{3} \mathrm{NP}$ as seen on TEM and FESEM are important characteristics for effective loading of OTC into it by physical adsorption mechanism (Fu et al., 2017). The soliddense appearance of OTC-CS-CaCO${ }_{3} \mathrm{NP}$ indicates the presence of OTC within the nanoparticles. When comparing the zeta size with TEM size, it can deduce that both followed a similar pattern of low and high sizes for CS-CaCO ${ }_{3} \mathrm{NP}$ and OTC-CS-CaCO ${ }_{3} \mathrm{NP}$, respectively. Although there is a marked difference in the actual sizes quoted by both techniques. The Zeta size measures the apparent size as the particles move in fluid (Brownian motion), thus measuring not only the particle but concentric layers of fluid around it (i.e., hydrodynamic diameter) resulting in exaggerated

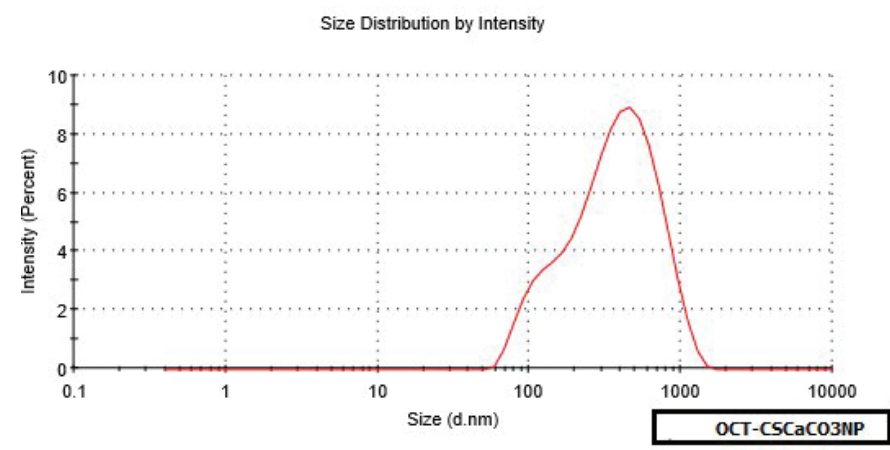

Figure 3. Zeta size distribution of OTC-CSCaCO${ }_{3} \mathrm{NP}$.

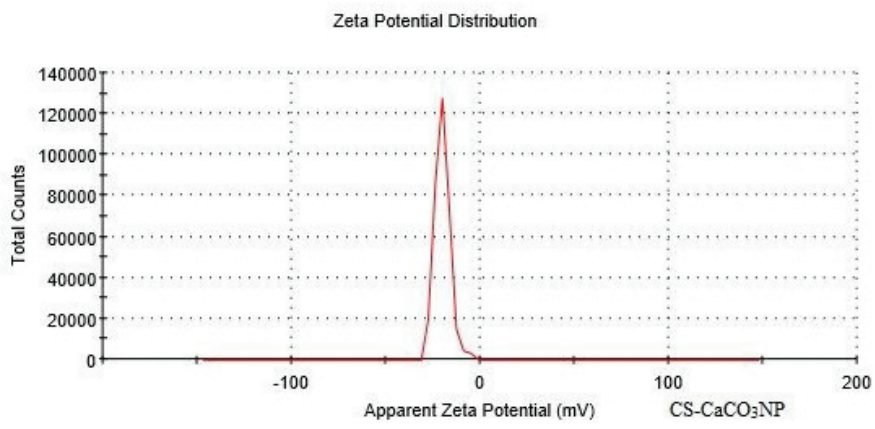

Figure 4. Zeta potential distribution of $\mathrm{CS}-\mathrm{CaCO}_{3} \mathrm{NP}$.

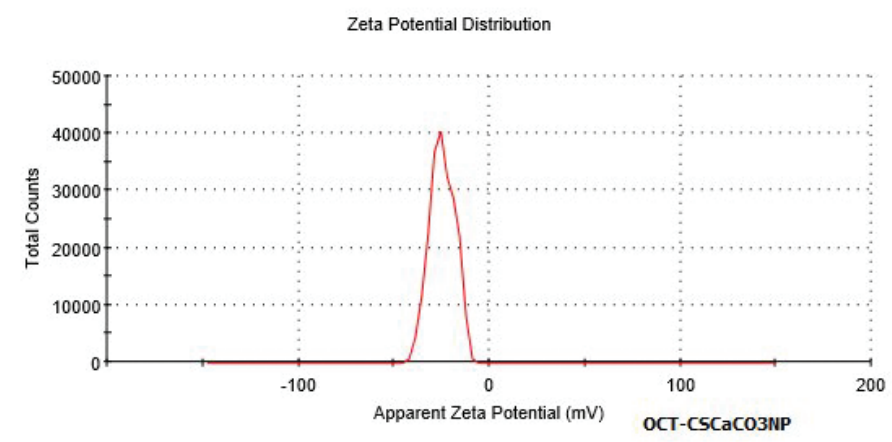

Figure 5. Zeta potential distribution of $\mathrm{CS}-\mathrm{CaCO}{ }_{3} \mathrm{NP}$.

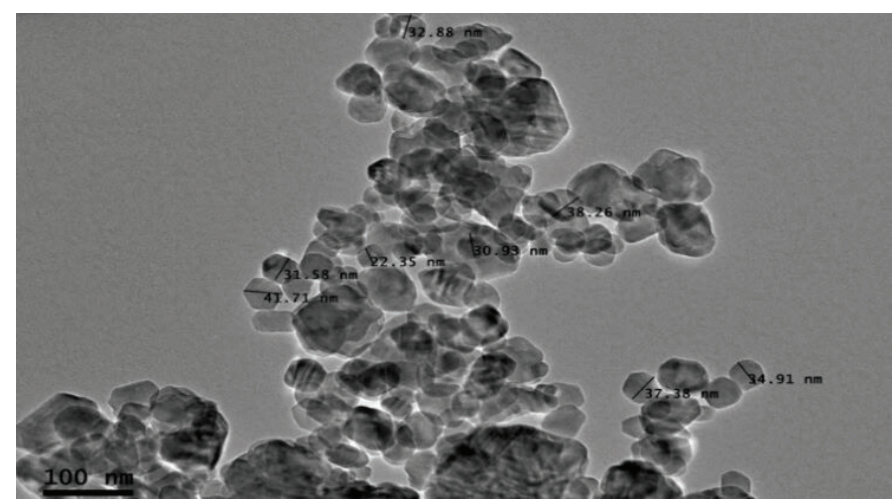

Figure 6. Photomicrograph of cockle shell derived calcium carbonate aragonite nanoparticle $\mathrm{CS}-\mathrm{CaCO}_{3} \mathrm{NP}$ ) on transmission electron microscope showing the nanoparticle sizes ranging from 17.6 to $41 \mathrm{~nm}$. 


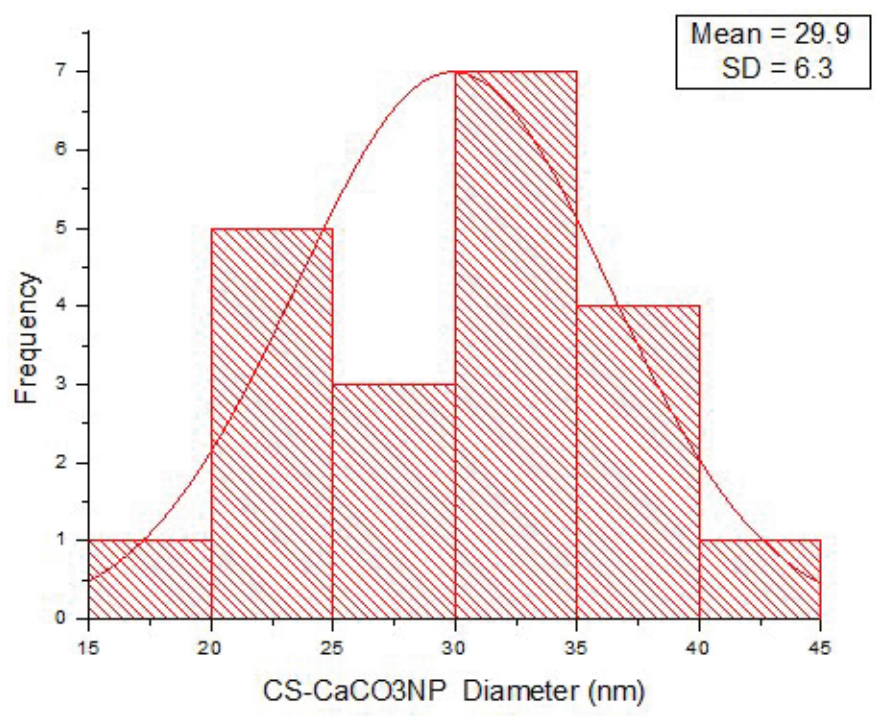

Figure 7. Average diameter, size, and distribution of $\mathrm{CS}-\mathrm{CaCO}_{3} \mathrm{NP}$ on TEM.

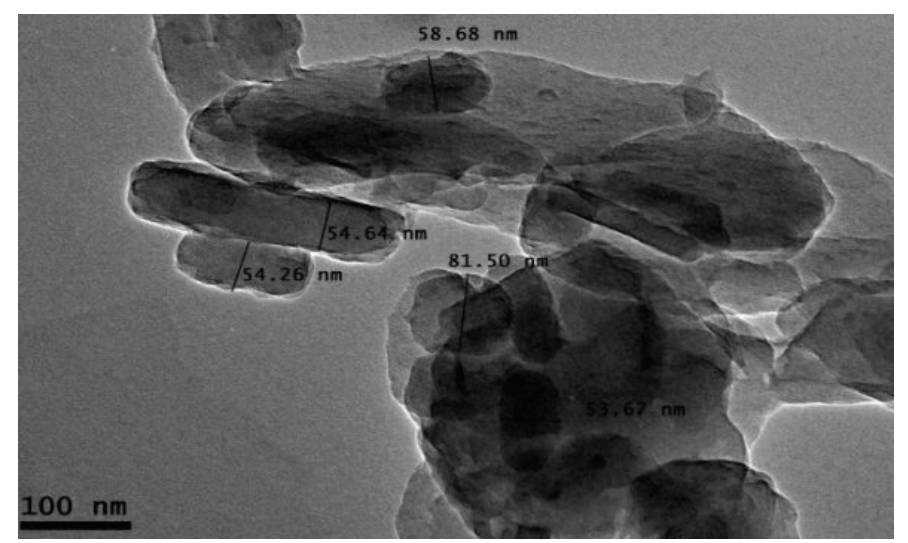

Figure 8. Photomicrograph of oxytetracycline loaded cockle shell derived calcium carbonate aragonite nanoparticle (OTC-CS-CaCO ${ }_{3} \mathrm{NP}$ ) on transmission electron microscope showing an average nanoparticle size of $53.73 \mathrm{~nm}$.

size values. On the other hand, in TEM which is another method for measuring size, the air drying of $\mathrm{CS}-\mathrm{CaCO}_{3} \mathrm{NP}$ and OTC$\mathrm{CS}-\mathrm{CaCO}_{3} \mathrm{NP}$ on the gold palladium after sonicating in distilled water during sample preparation resulted in a reduction in the size of the nanoparticles (Motwani et al., 2008).

Elemental analysis of $\mathrm{CS}-\mathrm{CaCO}_{3} \mathrm{NP}$ and OTC-CS$\mathrm{CaCO}_{3} \mathrm{NP}$ (Tables 2 and 3) showed high amounts of oxygen, carbon, and calcium in decreasing order. This is in line with the chemical formula $\left(\mathrm{CaCO}_{3}\right)$ with oxygen being the highest. For $\mathrm{CS}-\mathrm{CaCO}_{3} \mathrm{NP}$, carbon, oxygen, and calcium together account for $95.3 \%$ of the total elemental composition while the other elements ( $\mathrm{Mg}, \mathrm{Na}, \mathrm{Al}, \mathrm{Si}$, and $\mathrm{K}$ ) make up the remaining $4.7 \%$. Similar findings were reported for $\mathrm{C}, \mathrm{O}$, and $\mathrm{Ca}$ by Kamba et al. (2013) and Islam et al. (2012). However, for OCT-CS-CaCO ${ }_{3} \mathrm{NP}$, the total elemental percentage for $\mathrm{C}, \mathrm{O}$, and $\mathrm{Ca}$ together is $91 \%$ while phosphorus alone is $5.6 \%$ and other elements $(\mathrm{Na}, \mathrm{Al}, \mathrm{Si}, \mathrm{K}$,

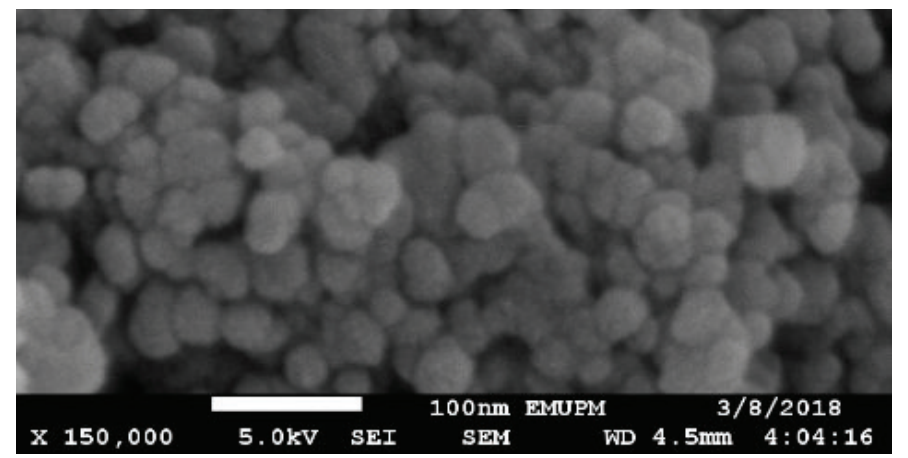

Figure 10. Field emission micrograph (FESEM) of spherically shaped CS$\mathrm{CaCO}_{3} \mathrm{NP}$

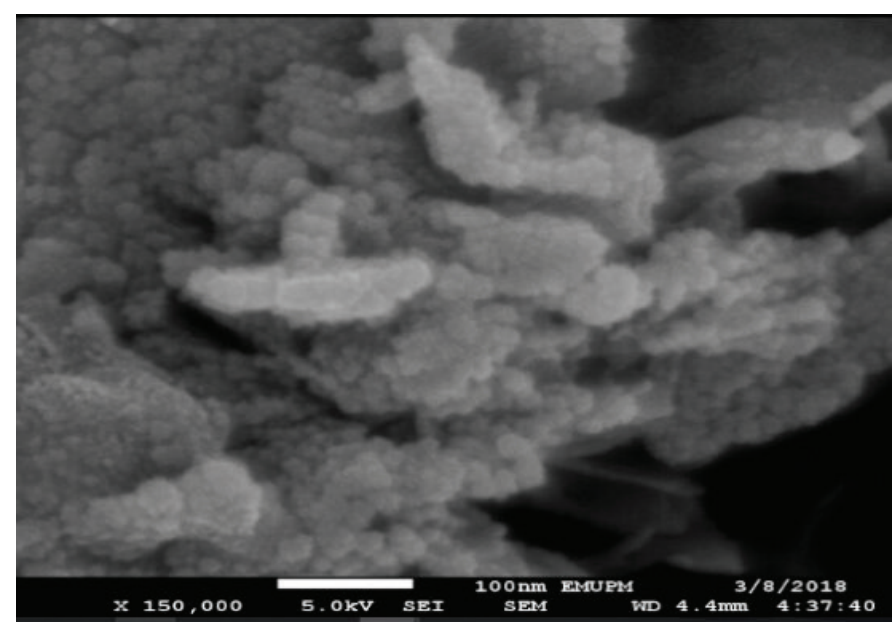

Figure 11. Field emission micrograph (FESEM) of spherically shaped OTC-CS$\mathrm{CaCO}_{3} \mathrm{NP}$. nanoparticle with the solid (dense) appearance.

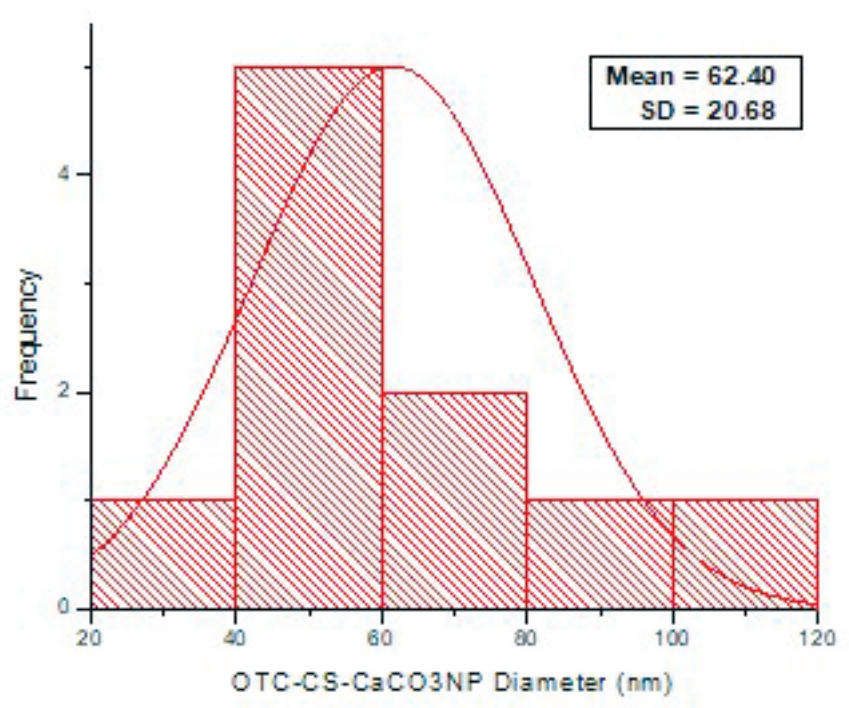

Figure 9. Average diameter, size, and distribution of OTC-CS-CaCO${ }_{3} \mathrm{NP}$ on TEM. 
Table 2. Elemental analysis of $\mathrm{CS}-\mathrm{CaCO}_{3} \mathrm{NP}$.

\begin{tabular}{cccccccccc}
\hline Spectrum & $\mathbf{C a}$ & $\mathbf{C}$ & $\mathbf{O}$ & $\mathbf{N a}$ & $\mathbf{M g}$ & $\mathbf{A l}$ & $\mathbf{S i}$ & $\mathbf{K}$ & Total \\
\hline 1 & 16.08 & 29.67 & 49.08 & 1.49 & 0.00 & 0.99 & 4.56 & 0.14 & 100 \\
2 & 13.79 & 29.06 & 53.96 & 0.85 & 0.00 & 0.72 & 1.63 & 0.00 & 100 \\
3 & 12.24 & 27.81 & 54.28 & 1.25 & 0.21 & 0.66 & 3.55 & 0.00 & 100 \\
Mean & 14.04 & 28.85 & 52.44 & 1.19 & 0.07 & 0.79 & 3.25 & 0.04 & \\
\pm SEM & 0.54 & 1.68 & 0.18 & 0.07 & 0.10 & 0.85 & 0.04 & 1.11 & \\
\hline
\end{tabular}

$\mathrm{Cl}$, and $\mathrm{Cu}$ ) make the remaining 3.4\%. The molecular formula of oxytetracycline hydrochloride is $\mathrm{C}_{22} \mathrm{H}_{25} \mathrm{CIN}_{2} \mathrm{O}_{9}$. Loading of OTC into $\mathrm{CS}-\mathrm{CaCO}_{3} \mathrm{NP}$ increased the percentage of carbon atoms while decreasing the amounts of oxygen and calcium present in CS$\mathrm{CaCO}_{3} \mathrm{NP}$. The concentration of elements that makes up $\mathrm{CaCO}_{3}$ is still high at $91 \%$ of the total amount of the elements that make up the nanoparticle loaded with drug loading with OTC did not change the composition of $\mathrm{CS}-\mathrm{CaCO}_{3} \mathrm{NP}$.

\section{FTIR and XRD analysis of CS-CaCO3NP, OTC-CS-CaCO3NP, and OTC}

The characteristic vibration of the different functional groups present in $\mathrm{CS}-\mathrm{CaCO}_{3} \mathrm{NP}$ and $\mathrm{OTC}$ were explained by FTIR analysis (Fig. 12). $\mathrm{CS}-\mathrm{CaCO}_{3} \mathrm{NP}$ showed its most prominent peak at $1,452 \mathrm{~cm}^{-1}$. This peak vibration corresponds to the alkyl group of CS-CaCO${ }_{3} \mathrm{NP}$ (Islam et al., 2012; 2013) and is due to the $\mathrm{C}=\mathrm{O}$ stretching vibration in the alkyl group. $\mathrm{CO}_{3}{ }^{2-}$ peak that is characteristic of aragonite $\mathrm{CS}-\mathrm{CaCO}_{3} \mathrm{NP}$ were seen at 1,072.29, 854.77 , and $707.58 \mathrm{~cm}^{-1}$, respectively. The spectra of free OTC showed characteristic absorption bands at 1,010.64-1,622.76 cm which is attributed to the $\mathrm{C}=\mathrm{O}$ and $\mathrm{C}=\mathrm{C}$ bonds of the aromatic structure of OTC. The vibration at $1,622.76 \mathrm{~cm}^{-1}$ is attributed to the $\mathrm{C}=\mathrm{N}-\mathrm{H}$ groups while that seen with peak at 3,317.91 is due to the $\mathrm{N}-\mathrm{H}$ and $\mathrm{N}-\mathrm{C}$ absorption bands of the amine group. The spectral bands of OTC-CS-CaCO${ }_{3} \mathrm{NP}$ which were attributed to the OTC are seen at 1,248.87-1,609 $\mathrm{cm}^{-1}$, whereas bands located at $851,938.43,1,464$, and $1,609.71 \mathrm{~cm}^{-1}$ are those of amides while those at 1,020.03 and 1,248.87 are those resulting due to stretching of aromatic $\mathrm{C}==\mathrm{C}$. The bands seen between 1,200 and $1,600 \mathrm{~cm}^{-1}$ in the free OTC are also present within the OTC-CS-CaCO${ }_{3} \mathrm{NP}$ bands. The characteristic $\mathrm{CO}_{3}{ }^{2-}$ of aragonite $\mathrm{CS}-\mathrm{CaCO}_{3} \mathrm{NP}$ between 860.16 meaning that the OTC did not react significantly with the $\mathrm{CS}-\mathrm{CaCO}_{3} \mathrm{NP}$ following loading suggesting dispersion of OTC molecules within the OTC-CS-CaCO${ }_{3} \mathrm{NP}$ (Larbi-Bouamrane et al., 2016).

The XRD diffractograms were done at $2 \Theta$ peak position to identify fingerprints of the crystal phase of samples ( $\mathrm{Ni}$ and Ratner, 2008). The XRD result pattern (Fig. 13) for $\mathrm{CS}-\mathrm{CaCO}_{3} \mathrm{NP}$ showed three strong peaks at $26.2^{\circ}, 45.8^{\circ}$, and $33.1^{\circ}$ at $2 \Theta$ degree while that of OTC-CS-CaCO${ }_{3} \mathrm{NP}$ also showed three strong peaks at $31.8^{\circ}, 32.4^{\circ}$, and $9.3^{\circ}$. These XRD diffractograms match with the International Centre for Diffraction Data database for aragonite crystals (JCPDS 00-141-1475). The appearance of two strong peaks of OTC-CS-CaCO${ }_{3} \mathrm{NP}$ very close to $33.1^{0}$ is evidence that loading OTC into $\mathrm{CS}-\mathrm{CaCO}_{3} \mathrm{NP}$ did not affect the crystallinity of the $\mathrm{CS}_{-} \mathrm{CaCO}_{3} \mathrm{NP}$ nanoparticle (Kamba et al., 2013; Danmaigoro et al., 2017). The first peak $\left(9.5^{\circ}\right)$ of free OTC corresponding to one of the strongest peaks in OTC-CS-CaCO${ }_{3} \mathrm{NP}$ is an indication that the drug is unaffected by loading into the nanoparticle.

\section{BET surface area, average pore diameter, and total pore volume of CaCO3NP}

The curve derived from the linear isotherm plot of $\mathrm{CaCO}_{3} \mathrm{NP}$ (Fig. 14) is convex to the $\mathrm{P} / \mathrm{Po}$ axis throughout its range which qualifies it to be classified as the reversible Type III isotherm based on the IUPAC classification of adsorption isotherms (IUPAC, 1980). Classifying $\mathrm{CaCO}_{3} \mathrm{NP}$ based on pore size, the average pore diameter $(185 \mathrm{~nm})$ is greater than $50 \mathrm{~nm}$; hence, the pore size of the $\mathrm{CaCO}_{3} \mathrm{NP}$ is biocompatible. The pore size is important for the adsorption of drugs into the nanoparticle because it enhances encapsulation efficiency and drug delivery (Xu et al., 2018). The large surface area of $8.4987 \pm 0.0922\left(\mathrm{~m}^{2} / \mathrm{g}\right)$ of the $\mathrm{CaCO}_{3} \mathrm{NP}$ compared to the pore volume $0.392931\left(\mathrm{~cm}^{3} / \mathrm{g}\right)($ Table 4$)$ is an important unique characteristic of nanoparticles which allows for close interactions with other molecules compared to their bulked size counterparts. A large total pore volume of $0.392931 \mathrm{~cm}^{3} / \mathrm{g}$ is referred to as the adsorptive space (IUPAC, 1980).

\section{Loading capacity and encapsulation efficiency of OTC}

The LC and EE of the loaded OTC-CS-CaCO${ }_{3} \mathrm{NP}$ are shown in Table 5. Increasing concentrations of OTC resulted in increased loading capacity and encapsulation efficiency with maximal drug loss. Increasing concentrations of OTC resulted in increased LC and EE with maximal drug loss. This is because higher drug concentrations imply higher LC and EE but with increased loss of drugs outside the nanoparticle over the capacity than the nanoparticle can hold. While with increasing nanoparticle weight, there was decreasing LC with increased $\mathrm{EE}$ and minimal drug loss. This is because loading drugs into $\mathrm{CS}-\mathrm{CaCO}_{3} \mathrm{NP}$ is a function of the weight of drugs fed into the nanoparticles in relation to the weight of the nanoparticles (Abd Ghafar et al., 2017; Muhamad and Selvakumaran, 2014). Incorporating drugs into $\mathrm{CS}-\mathrm{CaCO}_{3} \mathrm{NP}$ depends on capillary action and not on the surface charge and solubility of the drug (Jaji et al., 2017). The negative charge of $\mathrm{CS}-\mathrm{CaCO}_{3} \mathrm{NP}$ may be responsible for the adsorption of OTC due to the electrostatic interaction with the positively charged quaternary ammonium functional group of the OTC

Table 3. Elemental analysis of OTC-CS-CaCO${ }_{3} \mathrm{NP}$.

\begin{tabular}{cccccccccccc}
\hline Spectrum & $\mathbf{C a}$ & $\mathbf{C}$ & $\mathbf{O}$ & $\mathbf{C a}$ & $\mathbf{A l}$ & $\mathbf{S i}$ & $\mathbf{K}$ & $\mathbf{C l}$ & $\mathbf{C u}$ & $\mathbf{P}$ & Total \\
\hline 1 & 7.90 & 36.23 & 46.25 & 1.95 & 0.85 & 0.55 & 0.10 & 0.82 & 0.16 & 5.18 & 100 \\
2 & 8.18 & 36.87 & 45.09 & 2.04 & 0.95 & 0.52 & 0.00 & 0.87 & 0.00 & 5.49 & 100 \\
3 & 9.36 & 39.96 & 40.33 & 1.93 & 0.93 & 0.40 & 0.00 & 0.96 & 0.00 & 6.14 & 100 \\
Mean & 8.48 & 37.69 & 43.89 & 1.97 & 0.91 & 0.49 & 0.33 & 0.88 & 0.05 & 5.60 & 100 \\
\pm SEM & 0.44 & 1.15 & 1.81 & 0.03 & 0.03 & 0.05 & 0.06 & 0.03 & 0.05 & 0.28 & 100 \\
\hline
\end{tabular}




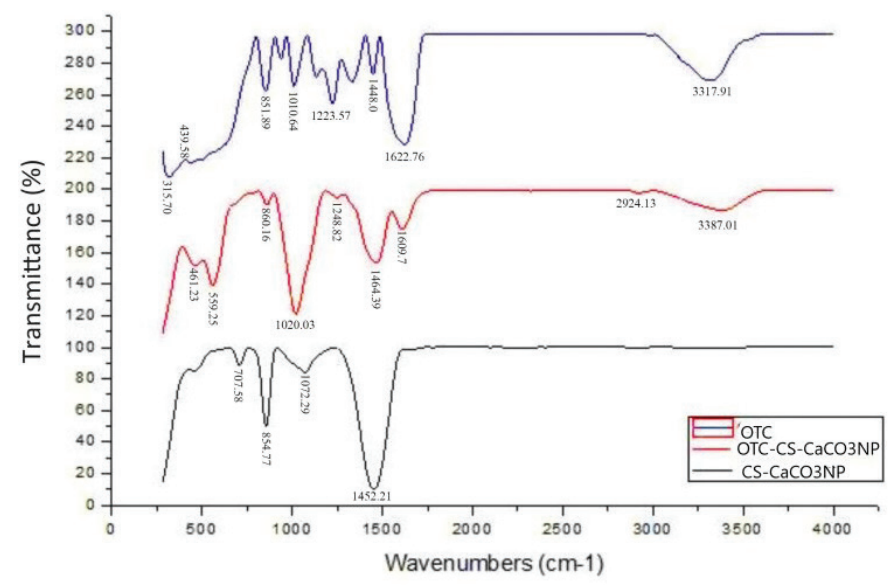

Figure 12. FTIR spectra of OTC, OTC-CS-CaCO $\mathrm{NP}$, and $\mathrm{CaCO}_{3} \mathrm{NP}$.

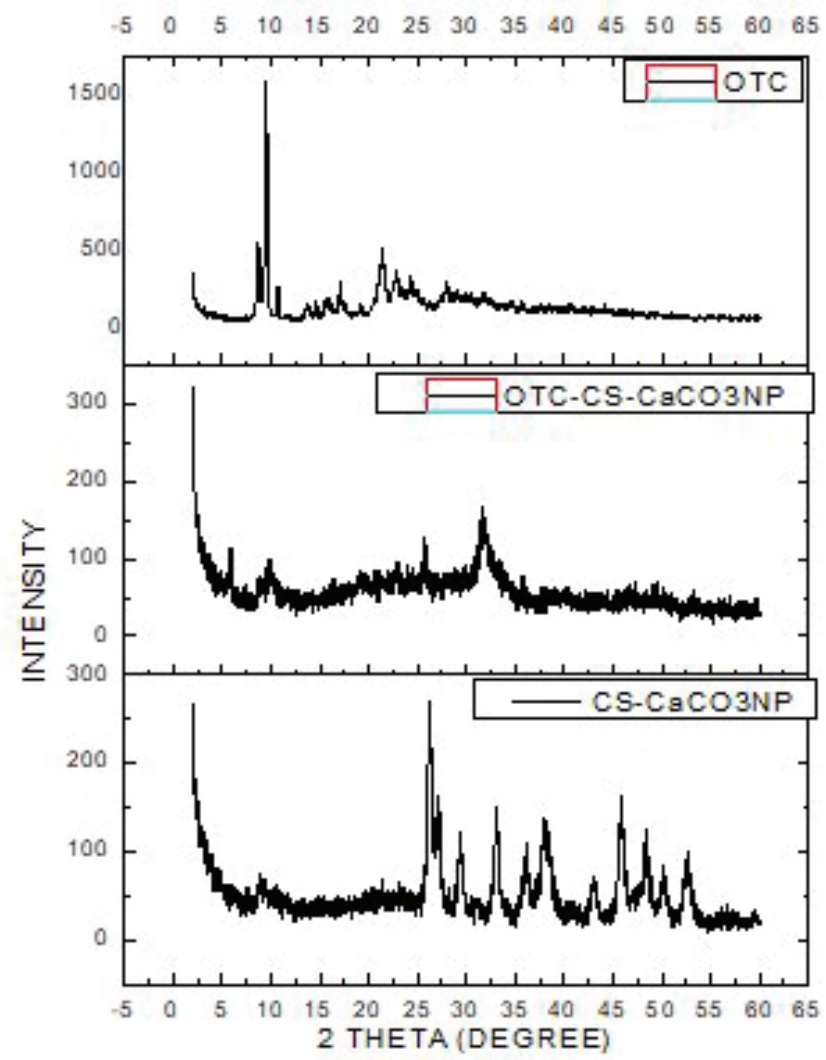

Figure 13. XRD spectra peak of OTC, OTC-CS-CaCO ${ }_{3} \mathrm{NP}$, and $\mathrm{CaCO}_{3} \mathrm{NP}$.

molecule (Harja and Ciobanu, 2018). Also, physical interaction like Van der Waals forces and hydrogen bonding between OTC and $-\mathrm{COOH}$ and $-\mathrm{OH}$ functional groups of $\mathrm{CS}-\mathrm{CaCO}_{3} \mathrm{NP}$ may have contributed to the adsorption of OTC into $\mathrm{CS}-\mathrm{CaCO}_{3} \mathrm{NP}$ (Deng et al., 2013). The pores on the $\mathrm{CS}-\mathrm{CaCO}_{3} \mathrm{NP}$ leading to tortuous channels within the nanoparticles which the drug is carried into and loading of OTC into the $\mathrm{CS}-\mathrm{CaCO}_{3} \mathrm{NP}$ overnight could be responsible for the high loading capacity as the drug had been absorbed into the calcium carbonate nanoparticle resulting

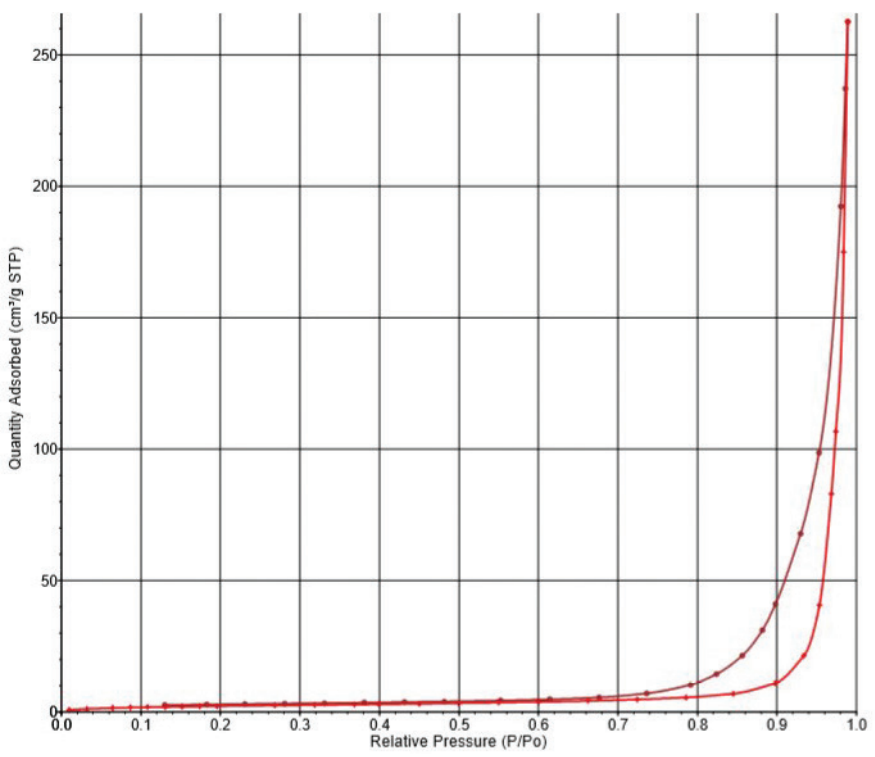

Figure 14. Adsorption-desorption isotherm linear plot of $\mathrm{CaCO} 3 \mathrm{NP}$ displaying the typical type III convex shape relative to the P/Po axis.

Table 4. BET surface area, average pore diameter, and total pore volume of $\mathrm{CaCO}_{3} \mathrm{NP}$.

\begin{tabular}{cccc}
\hline Nanoparticle & $\begin{array}{c}\text { BET surface area } \\
\left(\mathbf{m}^{\mathbf{2}} / \mathbf{g}\right)\end{array}$ & $\begin{array}{c}\text { Average pore } \\
\text { diameter }(\mathbf{\AA})\end{array}$ & $\begin{array}{c}\text { Total pore volume at } \mathbf{P} / \mathbf{P o} \\
\mathbf{= 0 . 9 8 8 5 0 0 0 0 0}\left(\mathbf{c m}^{\mathbf{3}} / \mathbf{g}\right)\end{array}$ \\
\hline $\mathrm{CaCO} 3 \mathrm{NP}$ & $8.4987 \pm 0.0922$ & $1,849.3728$ & 0.39 \\
\hline
\end{tabular}

Table 5. Loading content and encapsulation efficiency of $\mathrm{OTC}-\mathrm{CaCO}_{3} \mathrm{NP}$ ratios.

\begin{tabular}{cccccc}
\hline $\begin{array}{c}\text { OTC:CS- } \\
\text { CaCO3NP }\end{array}$ & $\begin{array}{c}\text { Weight } \\
\text { of OTC } \\
(\mathbf{m g})\end{array}$ & $\begin{array}{c}\text { Weight of } \\
\text { CS-CaCO3NP } \\
(\mathbf{m g})\end{array}$ & $\begin{array}{c}\text { Loading } \\
\text { content }(\%)\end{array}$ & $\begin{array}{c}\text { Encapsulation } \\
\text { efficiency (\%) }\end{array}$ & PDI \\
\hline $1: 1$ & 5 & 5 & 71.2 & 71.2 & 0.32 \\
$2: 1$ & 10 & 5 & 171.4 & 85.7 & 0.33 \\
$3: 1$ & 15 & 5 & 268.8 & 89.6 & 0.35 \\
$1: 2$ & 5 & 10 & 35.8 & 71.6 & 0.31 \\
$1: 3$ & 5 & 15 & 23.9 & 71.7 & 0.33 \\
$1: 4$ & 5 & 20 & 17.9 & 71.8 & 0.31 \\
\hline
\end{tabular}

expansion and subsequent increase in size and dark hollow centers seen in the OTC-CS-CaCO${ }_{3} \mathrm{NP}$ on TEM.

\section{In vitro OTC release from OTC-CS-CaCO3NP}

The essence of loading drugs into carriers is not only to get them delivered to target sites but also ensure the maximum efficient release of the drug from the carrier so as to maintain a given concentration of the drug within the system during the course of therapy (Narayan et al., 2012). Release study (Fig. 15) shows a fast release (99.4\%) over 3 hours for free OTC at $\mathrm{pH}$ 4. The solubility of free OTC in deionized water makes it easier and faster to diffuse through the membrane to reach the medium from which the concentration was determined. However, for OTC-CS-CaCO $\mathrm{NP}$, there was an initial rapid "burst" release from 0 to 8 hours, with a gradual and steady release over the rest of the 96 hours of the release profiles for the $\mathrm{pH} 4,6,7.4$, and 8 


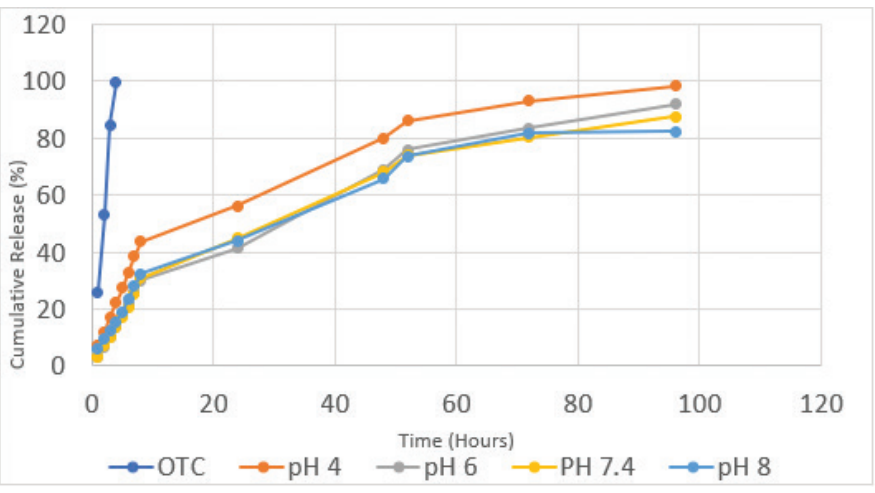

Figure 15. In vitro oxytetracycline release profile from $\mathrm{OTC}-\mathrm{CS}-\mathrm{CaCO}_{3} \mathrm{NP}$.

tested. The release was highest for $\mathrm{pH} 4$ (98.2) and 6.0 (91.8\%) when compared to $\mathrm{pH} 7.4(87.7 \%)$ and $8.0(82.4 \%)$. The release of OTC at different $\mathrm{pH}$ indicates that $\mathrm{CS}-\mathrm{CaCO}_{3} \mathrm{NP}$ is an efficient carrier which can maintain the concentrations of antibiotic during infections as compared to the free antibiotic release (Pan et al., 2018). This high amount of OTC released from OTC-CS$\mathrm{CaCO}_{3} \mathrm{NP}$ at $\mathrm{pH} 4$ may be attributable to the high solubility of OTC in acidic media as mentioned by Larbi-Bouamrane et al. (2016)

The slow release of OTC from OTC-CS-CaCO $3 \mathrm{NP}$ implies that encapsulation of OTC into colloids creates a better microenvironment which results in slow release of OTC over a longer period when compared with free OTC release (FaustinoVega et al., 2009). Furthermore, the initial burst release followed by the gradual steady release of OTC from OTC-CS-CaCO ${ }_{3} \mathrm{NP}$ suggest that $\mathrm{OTC}-\mathrm{CS}-\mathrm{CaCO}_{3} \mathrm{NP}$ is a core-shell structure $\mathrm{Xu}$ et al., 2011), with the OTC adsorbed on the surface (Shell) of CS$\mathrm{CaCO}_{3} \mathrm{NP}$ been released rapidly, while OTC loaded in the innercore could only be released slowly from OTC-CS-CaCO $\mathrm{NP}_{3}$ via the pores through dissolution and diffusion (Larbi-Bouamrane et al., 2016; Narayan et al., 2012). Earlier studies of drug release from $\mathrm{CS}-\mathrm{CaCO}_{3} \mathrm{NP}$ showed slow decomposition and release rate at $\mathrm{pH} 7.4$ and faster at $\mathrm{pH}>6.5$ (Dijaz et al., 2015).

\section{CONCLUSION}

In the present study, OTC-CS-CaCO${ }_{3} \mathrm{NP}$ drug formulation was designed. The formulation was characterized morphologically and pharmacologically employing Zeta, FESEM, TEM, FTIR, XRD, and BET with drug loading and release studies. Mean size of $\mathrm{CaCO}_{3} \mathrm{NP}$ and OTC-CS-CaCO${ }_{3} \mathrm{NP}$ was approximately $29.90 \pm 6.30$ and $62.40 \pm 20.68$, respectively, with sustained in vitro release at $\mathrm{pH} 4.0,6.0,7.4$, and 8.0. Results from this work provide a basis to further probe the cytocompatibility and antibacterial effect of the synthesized OTC-CS-CaCO${ }_{3} \mathrm{NP}$ formulation.

\section{FINANCIAL SUPPORT}

This study was supported by Geran Putra, Universiti Putra Malaysia (Grant Code: GP/2018/9616700).

\section{CONFLICTS OF INTEREST}

The authors declare that there is no conflict of interest.

\section{REFERENCES}

Abd Ghafar SLM, Hussein MZ Zuki AZ. Synthesis and characterization of cockle shell-based calcium carbonate aragonite polymorph nanoparticles with surface functionalization. J Nanoparticles, 2017; 2017:1-12

Adhikari MD, Goswami S, Panda BR, Chattopadhyay A, Ramesh A. Membrane-directed high bactericidal activity of (gold nanoparticle)polythiophene composite for niche applications against pathogenic bacteria. Adv Healthc Mater, 2013; 2:599-606.

Arvizo RR, Miranda OR, Moyano DF, Walden CA, Giri K, Bhattacharya R, Robertson JD, Rotello VM, Reid JM, Mukherjee P. Modulating pharmacokinetics, tumor uptake and biodistribution by engineered nanoparticles. PLoS One, 2011; 6:3-8.

Chakraborty SP, Sahu SK, Pramanik P. Biocompatibility of folate-modified chitosan nanoparticles. Asian Pac J Trop Biomed, 2012; $2: 215-9$.

Danmaigoro A, Selvarajah GT, Hezmee MNM, Mahmud R, Zuki AZ. Development of cockleshell (Anadara granosa) derived $\mathrm{CaCO} 3$ nanoparticle for doxorubicin delivery. J Comput Theor Nanosci, 2017; 14:5074-86.

Das S, Chaudhury A. Recent advances in lipid nanoparticle formulations with solid matrix for oral drug delivery. AAPS Pharm Sci Tech, 2011; 12:62-76.

Deng, H, Shen XC, Wang XM, Du C. Calcium carbonate crystallization controlled by functional groups: a mini-review. Front Mater Sci, 2013; 7(1); doi 10.1007/s11706-013-0191-y

Dhand C, Dwivedi N, Loh XJ, Ying ANJ, Verma NK, Beuerman RW, Lakshminarayanan R, Ramakrishna S. Methods and strategies for the synthesis of diverse nanoparticles and their applications: a comprehensive overview. RSC adv, 2015; 5:105003-37.

Dijaz SM, Jalali MB, Zarrintan MH, Adibkhia KM, Lotfipour F. Calcium carbonate nanoparticles as cancer drug delivery system. Expert Opin Drug Deliv, 2015; 12:1649-60.

Faustino-Vega A, Alvarez-Polo MA, Gasca B, Bernad-Bernad M. Influence of three different colloidal systems on the oxytetracyclinelecithin behaviour. Pharmazie, 2009; 64:505-9.

Fu W, Hezmee MNM, Yusof LM, Ibrahim TAT, Keong YS, Jaji $\mathrm{AZ}$, Zuki AZ. In vitro evaluation of a novel $\mathrm{pH}$ sensitive drug delivery system-based cockle shell-derived aragonite nanoparticles against osteosarcoma. J Exp Nanosci, 2017; 12:166-87.

Harja M, Ciobanu G. Science of the total environment studies on adsorption of oxytetracycline from aqueous solutions onto hydroxyapatite Sci Total Environ, 2018; 628-629:36-43.

Isa T, Zuki AZ, Rukayadi Y, Hezmee MNM, Jaji AZ, Imam MU, Hammadi IN, Mahmood SK. Antibacterial activity of ciprofloxacinencapsulated cockle shells calcium carbonate (aragonite) nanoparticles and its biocompatibility in macrophage J774A. IJMS, 2016; 17:713-30.

Islam KN, Zuki AZ, Ali ME, Hussein MZB, Noordin MM, Loqman MY, Islam A, Islam MS, Rahman MM, Ullah M. A novel method for the synthesis of calcium carbonate (aragonite) nanoparticles from cockle shells. Powder Technol, 2013; 235:70-5.

Islam KN, Zuki AZ, Ali ME, Hussein MZB, Noordin MM, Loqman MY, Wahid H, Hakim MA, Abd Hamid SB. Facile synthesis of calcium carbonate nanoparticles from cockle shells. J Nanomater, 2012; 2012:1-5.

IUPAC. Commission on colloid and surface chemistry including catalysis. Pure Appl Chem, 1982; 11:2201-18.

Jaji AZ, Zuki AZ, Mahmud R, Loqman MY, Hezmee MNM, Isa $T$, Wenliang F, Hammadi IN. Synthesis, characterization, and cytocompatibility of potential cockle shell aragonite nanocrystals for osteoporosis therapy and hormonal delivery. Nanotechnol Sci Appl, 2017; $1: 23-33$.

Kamba S, Ismail M, Hussein-Al-Ali S, Ibrahim T, Zuki, AZ. In Vitro delivery and controlled release of doxorubicin for targeting osteosarcoma bone cancer. Molecules, 2013; 18:10580-98. 
Larbi-Bouamrane O, Bal Y, Aliouche D, Cote G, Chagnes A. Preparation and Characterization of cross-linked chitosan microcapsules for controlled delivery of oxytetracycline. Indian J Pharm Sci, 2016; 78:71524.

Liu F, Wu J, Chen K, Xue D. Morphology study by using scanning electron microscopy. In: Méndez-Vilas A, Díaz, J (eds.). Science, technology, applications and education, Formatex Research Center, Badajoz, Spain, vol 3, pp 1783-92.

Masarudin MJ, Cutts SM, Evison BJ, Pigram PJ. Factors determining the stability, size distribution, and cellular accumulation of small monodisperse chitosan nanoparticles as candidate vectors for anticancer drug delivery: application to the passive encapsulation of [14 C]-doxorubicin. Nanotechnol Sci Appl, 2015; 8:67-80.

Motwani SK, Chopra S, Talegaonkar S, Kohli K, Ahmad FJ. Chitosan-sodium alginate nanoparticles as submicroscopic reservoirs for ocular delivery: formulation, optimisation and in vitro characterisation. Eur J Pharm Biopharm, 2008; 68:513-25.

Muhamad II, Selvakumaran S. Designing polymeric nanoparticles for targeted drug delivery system outline. Nanomedicine, 2014; 11:287-313.

Murdock RC, Braydich-Stolle L, Schrand AM, Schlager JJ, Hussain SM. Characterization of nanomaterial dispersion in solution prior to in vitro exposure using dynamic light scattering technique. Toxicol Sci, 2008; 101:239-53.

Narayanan D, Anitha A, Jayakumar R, Nair SV, Chennazhi KP. Synthesis, characterization and preliminary in vitro evaluation of PTH 1-34 loaded chitosan nanoparticles for osteoporosis. J Biomed Nanotech, 2012; 8:98-106.

Ni M, Ratner B. Differentiation of calcium carbonate polymorphs by surface analysis technique - An XPS and TOF-SIMS study. Surf Interface Anal, 2008; 40:1356-61.

Othman NH, Abu Bakar BH, Don MM, Johari MAM. Cockle shell ash replacement for cement and filler in concrete. MJCE, 2013; 25:200-11.
Pan X, Chen S, Li D, Rao W, Zheng Y, Yang Z. The Synergistic antibacterial mechanism of gentamicin-loaded $\mathrm{CaCO}_{3}$ nanoparticles. Front Chem, 2018; 5:1-9.

Priyadarshana G, Kottegoda N, Senaratne A, deAlwis A, Karunaratne V. Synthesis of magnetite nanoparticles by top-down approach from a high purity ore. J Nanomater, 2015; 1-8.

Rawat P, Rajput YS, Bharti MK, Sharma R.A. Method for synthesis of gold nanoparticles using 1-amino-2naphthol-4-sulphonic acid as reducing agent. Curr Sci, 2016; 110:2297-300.

Razalia NIM, Pramanika S, Abu Osmana N, Radzib Z, PingguanMurphya B. Conversion of calcite from cockle shells to bioactive nanorod hydroxyapatite for biomedical applications. JCPR, 2016; 17:699-706.

Saidykhan L, Zuki AZ, Rukayadi Y, Kura AU, Latifah SY. Development of nanoantibiotic delivery system using cockle shell-derived aragonite nanoparticles for treatment of osteomyelitis. IJN, 2016; 11:66173

Xu W, Pengjin G, Zhang N, Liu X, Xie J. Macroporous silica nanoparticles for delivering $\mathrm{Bcl} 2$-function converting peptide to treat multidrug resistant-cancer cells. J Colloid Interface Sci, 2018; 527:141-50.

Xu X, Wang Y, Chen R, Feng C, Yao F, Tong S, Wang L, Yamashita $\mathrm{F}$, Yu J. Formulation and pharmacokinetic evaluation of tetracycline-loaded solid lipid nanoparticles for subcutaneous injection in mice. Chem Pharm Bull, 2011; 59:260-5.

\section{How to cite this article:}

Idris SB, Arifah AK, Jesse FFA, Ramanoon SZ, Basit MA,

Zakaria ZA, Zakaria MZAB. Synthesis, characterization, and in vitro release of oxytetracycline loaded in $\mathrm{pH}$-responsive $\mathrm{CaCO}_{3}$ nanoparticles. J Appl Pharm Sci, 2019; 9(11):019-027. 